\title{
Skin lesions caused by sporotrichosis
}

\author{
Lei Yu MD, Tang-De Zhang MD \\ Cite as: CMAJ 2021 July 26;193:E1139. doi: 10.1503/cmaj.202688
}

A 47-year-old, previously healthy woman presented to our dermatology clinic with a 3-month history of multiple nodules on her left hand and arm. She had first noticed a single painless nodule on her left forefinger at the site of a mild puncture wound that had occurred when she was planting trees. She had been treated with azithromycin, but the nodule had not resolved. Further nodules had developed, and when we examined her, she had multiple beaded nodules on her left arm, from her forefinger to the upper arm, some of which had ulcerated (Figure 1A).

Lesion biopsy samples sent for fungal culture grew a glabrous white mould. Microscopic examination showed slender, branching septate hyphae and conidiophores (Figure 1B). Polymerase chain reaction (PCR) confirmed Sporothrix schenckii, and we diagnosed sporotrichosis. We prescribed itraconazole $100 \mathrm{mg} / \mathrm{d}$, and the lesions resolved completely in 3 months.

Sporotrichosis is a mycosis caused by S. schenckii, a dimorphic organism that is ubiquitous in soil. Humans are usually infected by the fungus through traumatic inoculation during outdoor activities. ${ }^{1}$ In North America, sporotrichosis most often develops in gardeners, especially those growing orchids and roses, though occupational risks also include Christmas tree farming, hay baling and masonry work. ${ }^{2}$ The most common clinical presentation is a lymphocutaneous pattern of nodules that develops via proximal spread from the primary inoculation site through the lymphatics. ${ }^{1}$ The first lesion can be difficult to distinguish from a common furuncle or boil caused by Staphylococcus aureus, but failure to respond to antibacterial drugs, coupled with proliferation of lesions, should raise consideration of lymphocutaneous sporotrichosis. Other conditions to consider on the differential diagnosis include nocardiosis, atypical mycobacteriosis and leishmaniasis, which can also present with inflammatory nodules along lymphatic vessels. ${ }^{3}$ Culture and PCR assay confirms the diagnosis, and sporotrichosis can be managed with itraconazole, potassium iodide, terbinafine and amphotericin B. ${ }^{4}$

\section{References}

1. Chakrabarti A, Bonifaz A, Gutierrez-Galhardo MC, et al. Global epidemiology of sporotrichosis. Med Mycol 2015;53:3-14.

2. Kauffman CA. Sporotrichosis. Clin Infect Dis 1999;29:231-6, quiz 237.

3. Tirado-Sánchez A, Bonifaz A. Nodular lymphangitis (sporotrichoid lymphocutaneous infections). Clues to differential diagnosis. J Fungi (Basel) 2018;4:56.

4. Orofino-Costa R, Macedo PM, Rodrigues AM, et al. Sporotrichosis: an update on epidemiology, etiopathogenesis, laboratory and clinical therapeutics. An Bras Dermatol 2017;92:606-20.

\section{Competing interests: None declared.}

This article has been peer reviewed.

The authors have obtained patient consent.

Affiliation: Department of Dermatology, Zhujiang Hospital of Southern Medical University, Guangzhou, China

Content licence: This is an Open Access article distributed in accordance with the terms of the Creative Commons Attribution (CC BY-NCND 4.0) licence, which permits use, distribution and reproduction in any medium, provided that the original publication is properly cited, the use is noncommercial (i.e., research or educational use), and no modifications or adaptations are made. See: https://creativecommons.org/ licenses/by-nc-nd/4.0/

Correspondence to: Tang-De Zhang, tdgz2017@163.com 